\title{
Improving intraoperative temperature management in elective repeat cesarean deliveries: a retrospective observational cohort study
}

Amie L. Hoefnagel', Kristen L. Vanderhoef', Anwar Anjum², Venkata Damalanka', Saurin J. Shah', Carol A. Diachun ${ }^{1}$ and Paul D. Mongan ${ }^{1 *}$

\begin{abstract}
Background: Inadvertent perioperative hypothermia $\left(<36^{\circ} \mathrm{C}\right)$ occurs frequently during elective cesarean delivery and most institutions do employ perioperative active warming. The purpose of this retrospective observational cohort study was to determine if the addition of preoperative forced air warming in conjunction with intraoperative underbody forced air warming improved core temperature and reducing inadvertent perioperative hypothermia during elective repeat elective cesarean delivery with neuraxial anesthesia.

Methods: We evaluated the addition of perioperative active warming to standard passive warming methods (preheated intravenous/irrigation fluids and cotton blankets) in 120 parturients scheduled for repeat elective cesarean delivery (passive warming, $n=60$ vs. active + passive warming, $n=60$ ) in a retrospective observational cohort study. The primary outcomes of interest were core temperature at the end of the procedure and a decrease in inadvertent perioperative hypothermia $\left(<36^{\circ} \mathrm{C}\right)$. Secondary outcomes were surgical site infections and adverse markers of neonatal outcome.

Results: The mean temperature at the end of surgery after instituting the active warming protocol was $36.0 \pm 0.5^{\circ} \mathrm{C}$ (mean \pm SD, $95 \% \mathrm{Cl} 35.9-36.1$ ) vs. $35.4 \pm 0.5^{\circ} \mathrm{C}$ (mean \pm SD, 95\% Cl 35.3-35.5) compared to passive warming techniques $(p<0.001)$ and the incidence of inadvertent perioperative hypothermia at the end of the procedure was less in the active warming group - $68 \%$ versus $92 \%$ in the control group $(p<0.001)$. There was no difference in surgical site infections or neonatal outcomes.
\end{abstract}

Conclusions: Perioperative active warming in combination with passive warming techniques was associated with a higher maternal temperature and lower incidence of inadvertent perioperative hypothermia with no detectable differences in surgical site infections or indicators of adverse neonatal outcomes.

Keywords: Inadvertent hypothermia, Cesarean section, Quality improvement, Forced air warming, Anesthesia, Obstetrical, Body temperature, $\mathrm{MH}$ - cesarean section/*methods, Intraoperative complications/* ${ }^{*}$ revention \& control, Perioperative care

\footnotetext{
* Correspondence: paul.mongan@jax.ufl.edu

'Department of Anesthesiology, University of Florida College of Medicine -

Jacksonville, 655 West 8th Street; Box C-72, Jacksonville, FL 32209, USA

Full list of author information is available at the end of the article
}

(c) The Author(s). 2020 Open Access This article is licensed under a Creative Commons Attribution 4.0 International License, which permits use, sharing, adaptation, distribution and reproduction in any medium or format, as long as you give appropriate credit to the original author(s) and the source, provide a link to the Creative Commons licence, and indicate if changes were made. The images or other third party material in this article are included in the article's Creative Commons licence, unless indicated otherwise in a credit line to the material. If material is not included in the article's Creative Commons licence and your intended use is not permitted by statutory regulation or exceeds the permitted use, you will need to obtain permission directly from the copyright holder. To view a copy of this licence, visit http://creativecommons.org/licenses/by/4.0/ The Creative Commons Public Domain Dedication waiver (http://creativecommons.org/publicdomain/zero/1.0/) applies to the data made available in this article, unless otherwise stated in a credit line to the data. 


\section{Introduction}

Inadvertent perioperative hypothermia in the general surgical population (core temperature $<36^{\circ} \mathrm{C}$ ) is associated with complications ranging from bleeding and cardiac dysfunction to increased infections [1-3]. Inadvertent perioperative hypothermia occurs in 60-90\% during cesarean delivery as a result of peripheral vasodilation, diminished regulatory vasoconstriction, and reduced shivering responses that promote heat redistribution during neuraxial anesthesia [4-8]. Furthermore, this may also result in decreases in neonatal temperature, umbilical blood $\mathrm{pH}$, Apgar scores and associated adverse outcomes [6,9-11]. Reducing the incidence of inadvertent perioperative hypothermia is a quality target by the Centers for Medicare \& Medicaid Services and the British National Institute of Health and Care Excellence [12]. While national obstetrical organizations have not addressed this concern, the Enhanced Recovery After Surgery Society recommends active warming in addition to passive warming strategies during cesarean delivery [6].

Numerous publications have documented favorable outcomes with forced-air warming, underbody warming blankets, and warmed intravenous/irrigation fluids [5, 11, 13-17]. Inadvertent perioperative hypothermia is still common with intraoperative active warming and may be further ameliorated with 15-30 min of preoperative active warming $[9,18,19]$.

In this study, we expanded our standard surgical active warming practice of preoperative (Bair Paws ${ }^{\mathrm{Tm}}$ Standard Warming Gown) and intraoperative active warming (Bair full access underbody blanket) for parturients undergoing repeat cesarean delivery with neuraxial anesthesia. The primary outcome measures were maternal temperature and incidence of inadvertent perioperative hypothermia $\left(<36{ }^{\circ} \mathrm{C}\right)$.

\section{Methods}

This retrospective observational cohort study was approved by the University of Florida-Jacksonville Institutional Review Board and waiver for individual patient consent was granted [20]. Our primary objectives were to determine if standardized implementation of pre- and intraoperative active warming (combined with warmed IV/irrigation fluids) versus standard passive warming positively impacted core temperature and the incidence of inadvertent perioperative hypothermia in parturients scheduled for elective repeat cesarean delivery. Secondary outcomes included wound complications, Apgar scores, and fetal cord blood $\mathrm{pH}$ and base excess. Data collection for baseline state of inadvertent perioperative hypothermia occurred between January and May 2017 and the active warming phase was instituted between June and October 2017. No industry funding supported this project and this manuscript adheres to the Squire 2.0 guidelines for reporting [21].

We evaluated 120 parturients undergoing elective repeat cesarean delivery at the University of FloridaJacksonville Labor and Delivery Suite - an urban safetynet hospital - between January and September of 2017. Exclusion criteria were patients: < 18 years of age; active labor; a diagnosis of abnormal placentation; preeclampsia or eclampsia; significant cardiopulmonary comorbidities; temperature $>37^{\circ} \mathrm{C}$, primary cesarean delivery or a diagnosis of/or clinical evidence suggesting a disorder of coagulation or infection. A sample size power analysis was performed using mean temperature differences $\left(0.5^{\circ} \mathrm{C}\right)$ and $\mathrm{SD}(0.4-0.5)$ from studies evaluating passive warming and active warming during cesarean delivery $[5,14,18,22]$. Using an alpha $=0.05$ and power $=0.80$, and an unpaired two-tailed Student's t-test the projected sample size (GPower 3.1) was 50 (large effect size) to 60 (moderate effect size) for each group [23, 24].

\section{Temperature management}

From January to the end of May 2017, we did not alter our routine standard passive warming practices in the preoperative and operative environment. Fresh warmed cotton blankets $\left(40^{\circ} \mathrm{C}\right)$ were offered in the preoperative unit. The labor and delivery operating room ambient temperature was set at $18-20^{\circ} \mathrm{C}$. Irrigation and intravenous fluids were prewarmed in a temperature-controlled cabinet $\left(40^{\circ} \mathrm{C}\right)$. Fresh warmed cotton blankets $\left(40{ }^{\circ} \mathrm{C}\right)$ were used over the shoulder and arms in the operating room before initiation of the neuraxial block. Additional warmed blankets were used on the upper chest and arms after positioning for surgery. These were replaced at the request of the patient during the procedure and rearranged to facilitate skin to skin bonding after delivery.

During the active warming phase (June-October 2017), we replaced all warmed cotton blankets with the $3 \mathrm{M}^{\mathrm{TM}}$ Bair Paws ${ }^{\mathrm{TM}}$ System model 875 (3 M Center, Building 275-4E-01 St. Paul, MN 55144-1000) and a Bair Paws $^{\mathrm{TM}}$ patient warming gown (81003) preoperatively $\left(40{ }^{\circ} \mathrm{C}\right.$ ) for $30-60 \mathrm{~min}$ before transfer to the operating room. Patients adjusted the unit to their preferred level of comfort. and were able to express thermal discomfort in the operating room allowing for adjustment of the temperature of the underbody warming blanket by the anesthesia team.

In the operating room the Bair Paws ${ }^{\text {тा }}$ patient warming gown was left in place, but disconnected and rearranged to facilitate the neuraxial block and skin to skin infant bonding. After induction of neuraxial anesthesia, surgical preparation, and draping, the $3 \mathrm{M}^{\mathrm{Tm}}$ Bair Hugger ${ }^{\mathrm{TM}}$ System model 775 and a full access underbody blanket (54500) set at $43{ }^{\circ} \mathrm{C}$ was used for active warming. No warmed cotton blankets were used in the OR during this period 
and patients were able to express thermal discomfort in the operating room allowing for adjustment of the temperature of the underbody warming blanket by the anesthesia team. In addition, the anesthesia team could reduce the delivered temperature based on their clinical judgment or if the foley temperature exceeded $37^{\circ} \mathrm{C}$ (consistent with our standard practice for general anesthetic cases using a forced air warming device).

\section{Anesthetic and operative management}

In the operating room, after positioning the patient seated and obtaining baseline blood pressure, heart rate, and oxygen saturation, the lower back was disinfected with povidone iodine solution and a sterile fenestrated drape placed. Either a single shot spinal (PENCAN ${ }^{\circ}$ B. Braun Medical Inc. 824 12th Avenue, Bethlehem, Pennsylvania 18,018) or combined spinal epidural anesthetic $\left(\right.$ ESPOCAN $^{\bullet}$ B. Braun Medical Inc.) was established using $12 \mathrm{mg}$ hyperbaric bupivacaine, $20 \mathrm{mcg}$ preservative free fentanyl, and $150 \mathrm{mcg}$ preservative free morphine.

Immediately after the initiation of neuraxial anesthesia, the patient was positioned supine with left uterine displacement and a Foley catheter inserted for measurement of core temperature. Fluid loading was not performed before or during the neuraxial anesthetic. Blood pressure target greater than $110 \mathrm{mmHg}$ (or within 20\% of baseline for patients with gestational hypertension) was primarily accomplished by a low dose phenylephrine infusion $(50 \mathrm{mcg} / \mathrm{min})$ initiated at the start of the anesthetic [25]. In addition, weight based administration of intravenous cephazolin $(2 \mathrm{~g}<120 \mathrm{~kg}$ or $3 \mathrm{~g}>120 \mathrm{~kg})$ was infused $60 \mathrm{~min}$ before skin incision.

Physiological measurements were recorded using a Nihon Koden BSM-6000 Monitor (Nihon Koden America 15,353 Barranca Parkway, Irvine, CA 92618) with automated electronic storage to the Epic ${ }^{\circ}$ electronic health record (Epic, 1979 Milky Way, Verona, Wisconsin 53, 593). Fluid therapy and medication administration were entered directly into the $\mathrm{Epic}^{\circ}$ anesthesia record. In addition to the time entering the room and placement of the neuraxial block, other times recorded were skin incision, uterine incision, delivery, placenta delivery, and time of exit from the operating room.

After birth, umbilical arterial blood was sampled for $\mathrm{pH}$ and base excess. In addition, a pediatrician determined Apgar scores at 1 and $5 \mathrm{~min}$. Neonatal birth weight was recorded.

\section{Temperature measurements}

In the preoperative and postoperative recovery area the patient's sublingual temperature was measured with a Welch Allyn Sure Temp Plus 690 oral thermometer (Welch Allyn Inc., Corporate Headquarters, 4341 State Street Road, Skaneateles Falls, NY 13153, calibration accuracy $0.1{ }^{\circ} \mathrm{C}$ at $36.0^{\circ} \mathrm{C}$ ). The operating room temperature was continuously measured via the $\mathrm{T} 2$ input of the Nihon Koden BSM-6000 using an ambient temperature probe. Core temperature was measured as soon as clinically feasible using a 14 Fr Bardex I.C. 400 Series temperature sensing Foley catheter (Bard Medical Division, 8195 Industrial Blvd. Covington, GA 30014, accuracy $+/-0.2^{\circ} \mathrm{C}$ at $37.0^{\circ} \mathrm{C}$ ). A Foley temperature probe was chosen for evaluation of temperature due to its superior accuracy to lingual and temporal artery scanning and comparative accuracy with tympanic membrane temperatures without the risk of discomfort or trauma from a tympanic membrane temperature probe [26-28].

\section{Statistical analysis}

Data was analyzed with $\mathrm{IBM}^{\circ} \mathrm{SPSS}^{\circ}$ and descriptive statistics expressed as mean \pm standard deviation, median (range), confidence interval, numbers, or percent as appropriate. Differences between groups for continuous, normally distributed variables were analyzed with an unpaired two-tailed Student's t-test (Kolmogorov-Smirnoff two sample test if the data was not normally distributed). Categorical variables and proportions were analyzed with chi-square or Fisher's exact tests. A $p$ value $<0.05$ was considered significant.

\section{Results}

Data was collected on 120 patients (Fig. 1). Table 1 lists the demographic, patient descriptors, surgical times, and intraoperative fluid volumes. During the study period there were 218 elective cesarean delivery performed. Ninety-eight patients were excluded from the evaluation due to inclusion criteria (62) or lack of personnel/equipment for implementation of active warming (36). There were no differences in maternal, gestational, or operative characteristics. All parturients were scheduled for repeat cesarean delivery with some parturients having bilateral tubal ligation and a small number of patients for repeat cesarean delivery involving multiple gestations (Table 1). The proportion of spinal and combined spinal epidural anesthesia for the operation were similar for both groups. Epidural dosing occurred in 6 patients in the active warming group and 4 in the passive warming group $(p=0.51$, chi square). In addition, there was no difference in the time from entry to the operating room to neuraxial block and Foley catheter to skin incision and delivery. There was no difference in crystalloid administration or quantitative blood loss.

Table 2 details the temperature differences. There was a small but significant difference in the preoperative oral temperature before presentation to the operating room in the active warming group. The time after operating room entry to obtain initial Foley catheter temperatures was similar $(24.6 \pm 0.4$ active warming vs $25.7 \pm 9.8$ 


\section{Process Improvement Enrollment Flow Diagram}

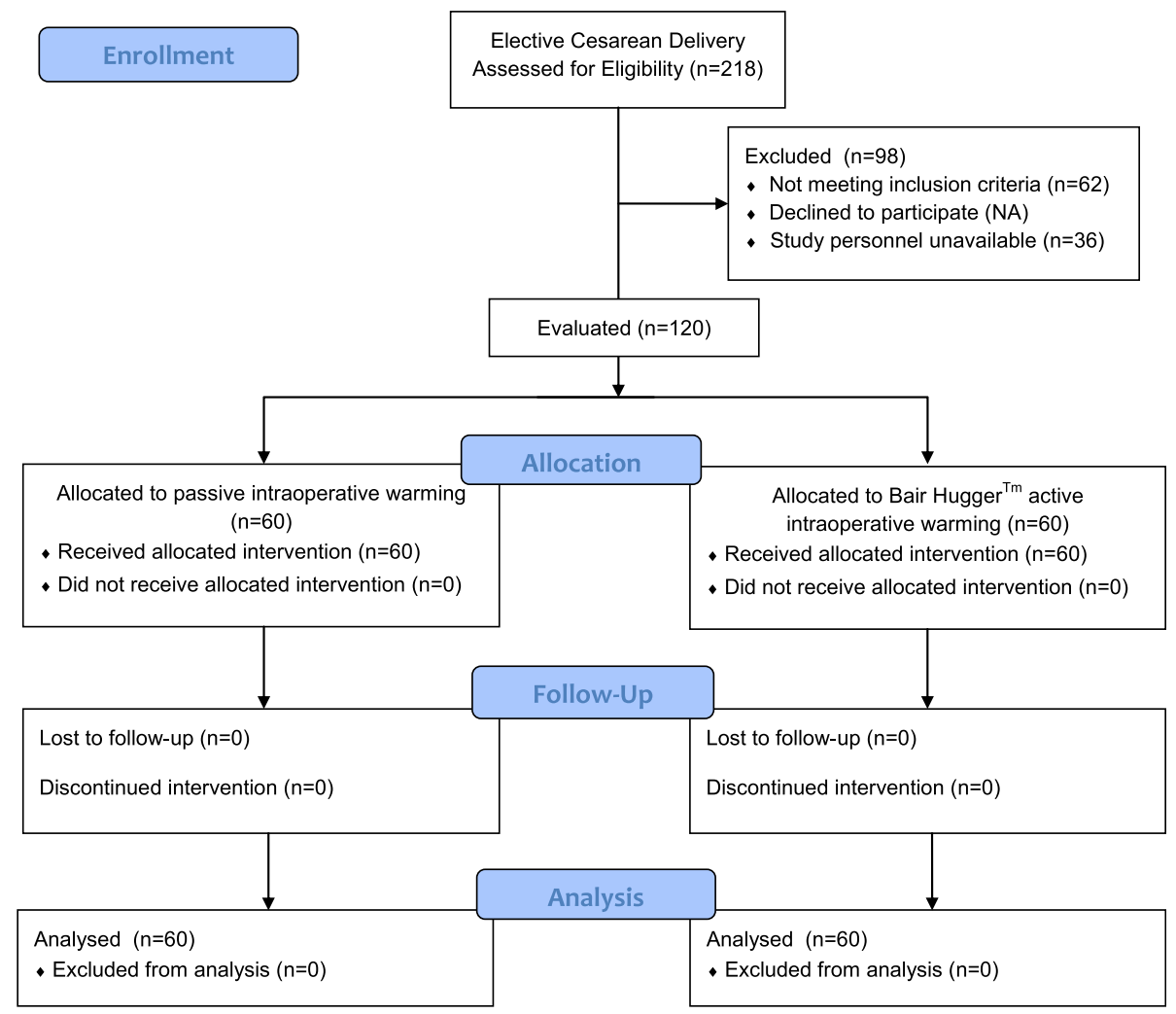

Fig. 1 Process Improvement Enrollment Flow Diagram

Table 1. Patient, Obstetric, Anesthetic And Surgical Variables.

\begin{tabular}{llll}
\hline & Forced Air Warming $(\mathrm{n}=60)$ & Passive Warming $(\mathrm{n}=60)$ & $P$ value \\
\hline Age (years) & $29.3 \pm 5.1$ & $29.4 \pm 6.4$ & 0.94 \\
Weight $(\mathrm{kg})$ & $96.4 \pm 29.9$ & $98.2 \pm 26.8$ & 0.73 \\
BMI $\left(\mathrm{kg} / \mathrm{m}^{2}\right)$ & $35.9 \pm 10.1$ & $36.5 \pm 8.8$ & 0.70 \\
ASA Score & $2(2,2)$ & $2(2,2)$ & $0.69^{\mathrm{KS}}$ \\
Gestational Age (days) & $273(266,274)$ & $273(271,275)$ & $0.89^{\mathrm{KS}}$ \\
Operation (repeat/BTL/twins) & $41 / 14 / 5$ & $47 / 11 / 2$ & $0.35^{\mathrm{chi}-\text { square }}$ \\
Spinal/CSE (n) & $21 / 39$ & $23 / 37$ & $0.84^{\mathrm{chi}-\text { square }}$ \\
Total Operating Room Time (min) & $110.0 \pm 33.5$ & $108.5 \pm 31.3$ & 0.77 \\
In Room to Foley Temp (min) & $24.6 \pm 9.5$ & $25.7 \pm 9.9$ & 0.54 \\
In Room to Skin Incision (min) & $37.5 \pm 11.1$ & $38.7 \pm 11.6$ & 0.52 \\
Skin Incision to Delivery (min) & $13(9,17)$ & $14(14,19)$ & $0.92^{\mathrm{KS}}$ \\
Uterine Incision to Delivery (min) & $2(1,2.75)$ & $1(1,2)$ & $0.98^{\mathrm{KS}}$ \\
Crystalloid Volume (ml) & $1832 \pm 489$ & $1745 \pm 474$ & 0.32 \\
Quantitative Blood Loss (ml) & $675(500,875)$ & $575(370,785)$ & $0.25^{\mathrm{KS}}$ \\
\hline
\end{tabular}

Data are expressed as average \pm standard deviation or median (25\%tile, $75 \%$ tile) or number (N/N/N).

Unless indicated a Student's t test was used to analyze differences between groups.

KS Kolmogorov Smirnoff two sample test of non-parametric data.

CSE combined spinal epidural.

$B T L$ bilateral tubal ligation. 
Table 2. Temperature Variables.

\begin{tabular}{|c|c|c|c|c|}
\hline & Forced Air Warming $(n=60)$ & Passive Warming $(n=60)$ & Effect Size Estimate & $P$ value \\
\hline Preoperative Temperature $\left({ }^{\circ} \mathrm{C}\right)$ & $36.8 \pm 0.3$ & $36.6 \pm 0.3$ & $0.7^{*}$ & $<0.005$ \\
\hline Operating Room Temperature $\left({ }^{\circ} \mathrm{C}\right)$ & $18.9 \pm 1.0$ & $18.7 \pm 1.2$ & $0.2^{*}$ & 0.19 \\
\hline Initial Foley Core Temperature $\left({ }^{\circ} \mathrm{C}\right)$ & $36.6 \pm 0.4$ & $36.5 \pm 0.4$ & $0.3^{*}$ & 0.38 \\
\hline Lowest Foley Core Temperature $\left({ }^{\circ} \mathrm{C}\right)$ & $35.6 \pm 0.5$ & $35.3 \pm 0.5$ & $0.7^{*}$ & $<0.005$ \\
\hline Final Foley Core Temperature $\left({ }^{\circ} \mathrm{C}\right)$ & $36.0 \pm 0.5$ & $35.4 \pm 0.5$ & $1.2^{*}$ & $<0.005$ \\
\hline Intraoperative Hypothermia $\left(<36^{\circ} \mathrm{C}, \mathrm{n}, \%\right)$ & $41,68 \%$ & $55,92 \%$ & $5.1^{+}$ & $<0.005$ \\
\hline Recovery Room Temperature $\left({ }^{\circ} \mathrm{C}\right)$ & $36.6 \pm 0.3$ & $36.3 \pm 0.3$ & $0.7^{*}$ & $<0.005$ \\
\hline
\end{tabular}

Data are expressed as average \pm standard deviation, number $(\mathrm{N})$, or percentage.

* $=$ Standardized Mean Difference

$+=$ Odds Ratio for temperature $<36^{\circ} \mathrm{C}$ without forced air warming

passive warming, min, $p=0.63)$ as were the initial temperatures (36.6 \pm 0.4 active warming vs $36.5 \pm 0.4$ passive warming, ${ }^{\circ} \mathrm{C}, p=0.38$ ). There was no difference in the number of patients with an initial core temperature > $36^{\circ} \mathrm{C}$ (59 and 56, active warming vs. passive warming respectively). There were subsequent differences with the lowest and final temperatures in the operating room (Table 2, $p<0.005$ ). In addition to differences in the lowest temperature, there was a difference in distribution with the active warming group maintaining temperatures above $36^{\circ} \mathrm{C}(n=18$ vs 5$)$ and the number of patients $<35^{\circ} \mathrm{C}$ in the passive warming group $(n=17$ vs 4 active warming, $p<0.0012 \mathrm{X} 4 \mathrm{FE}$ contingency table). At the end of surgery, the passive warming group continued to have 13 parturients $<35^{\circ} \mathrm{C}$ and $5>36^{\circ} \mathrm{C}$ while the active warming group had $0<35^{\circ} \mathrm{C}$ and $19>36^{\circ} \mathrm{C}$ ( $p<0.0012 \mathrm{X} 4 \mathrm{FE}$ contingency table). These measurements indicate that the loss of temperature in the operating room was minimized and the rewarming improved by active warming during the procedure. The time from the final Foley temperature in the operating room to the initial oral temperature in the recovery area was of short duration ( $6 \pm 4.3$ vs $7 \pm 4.7 \mathrm{~min}$, active warming vs passive warming). There were small statistically significant differences in the oral temperature measurements (36.6 \pm 0.3 and $36.3 \pm 0.3, p<0.001$ active warming vs passive warming) and no difference in the time to discharge from recovery. In Table 2, we also report the effect size of the temperature differences using the standardized mean difference (active warming mean passive warming mean)/pooled SD) [29]. The temperature differences in the preoperative and lowest intraoperative temperature reveal a moderate effect size (0.07) while the temperature differences at the end of surgery indicate a large effect. These differences were also evident in the odds ratio of 5.1 for inadvertent perioperative hypothermia in the passive warming group. Using the large and moderate effect size the number needed to treat to obtain the benefit from active warming vs passive warming is 2 to 5 [29].
Table 3 details the neonatal outcomes with no differences in birth weights, Apgar scores, or umbilical artery $\mathrm{pH}$ or base excess. With only a few exceptions, the umbilical artery measurements were within normal limits $(\mathrm{pH}<7.1$, none in the active warming and, 3 in passive warming group, chi square $\mathrm{p}=0.24)[16,30]$. Apgar scores $<7$ at 1 or $5 \mathrm{~min}$ were equivalent in both groups (active warming vs. passive warming $\mathrm{n}=3$ vs. 6 at $1 \mathrm{~min}$ $p=0.32$ and 2 vs. 0 at $5 \min p=0.49$ ).

In addition to neonatal outcomes, we reviewed all subsequent health care notes. All patients had outpatient post discharge post-partum visits (3-4 weeks postpartum) that documented wound status. There were no patients with either superficial or deep wound infections. In the passive warming group there was one patient with a wound seroma (not described) and one with slight induration that resolved without therapy. In contrast, in the active warming group there were 5 patients with small $(<1 \mathrm{~cm})$ area of wound dehiscence and 2 patients with wound seromas and dehiscence measuring 1 and $4.5 \mathrm{~cm}$. No patient received antibiotic therapy or had any apparent extra clinic or emergency department visits.

The datasets used and/or analyzed during the current study are available from the corresponding author on reasonable request.

\section{Discussion}

There are three findings related to active warming in addition to warmed IV/irrigation fluids before and during elective repeat cesarean delivery in this project. First, prewarming had a small positive impact on preoperative temperature that did not translate into higher initial core temperatures in the operating room. Second, active warming was associated with higher intraoperative and immediate postoperative temperature measurements. Third, the incidence of inadvertent perioperative hypothermia was less in the active warming group.

The use of spinal anesthesia with hyperbaric bupivacaine and morphine provides several challenges during cesarean delivery. The deleterious effects of spinal 
Table 3 Neonatal Outcomes

\begin{tabular}{|c|c|c|c|}
\hline & Forced Air Warming $(n=60)$ & Passive Warming $(n=60)$ & $P$ value \\
\hline Birth Weight (kg) & $3.2 \pm 0.6$ & $3.3 \pm 0.5$ & 0.13 \\
\hline Apgar 1 min & $9(8,9)$ & $9(8,9)$ & $0.99 \mathrm{KS}$ \\
\hline Apgar < 7 at $1 \min (n)$ & 3 & 7 & $p=0.32$ chi-square \\
\hline Apgar 5 min & $9(9,9)$ & $9(9,9)$ & $1.0^{\mathrm{KS}}$ \\
\hline Apgar $<7$ at 5 min (n) & 2 & 0 & $p=0.49$ chi-square \\
\hline Umbilical Arterial Blood pH & $7.24 \pm 0.06$ & $7.23 \pm 0.07$ & 0.18 \\
\hline Umbilical Arterial Blood pH < 7.1 (n) & 0 & 3 & $p=0.24^{\text {chi-square }}$ \\
\hline Base Excess & $-3.0 \pm 2.3$ & $-3.8 \pm 3.1$ & 0.16 \\
\hline
\end{tabular}

Data are expressed as average \pm standard deviation or median ( $25 \%$ tile, $75 \%$ tile).

Unless indicated an unpaired two tailed Student's t test was used to analyze differences between groups.

KS Kolmogorov Smirnoff two sample test of non-parametric data.

anesthesia on cutaneous vasodilation, redistribution of core body heat, and overall heat loss have been previously described $[7,8]$. The use of intrathecal morphine further exacerbates this effect [31]. In contrast, a continuous phenylephrine infusion, [25] the administration of fluids using fluid warmers [32-35] or a warming cabinet $\left(37-45^{\circ} \mathrm{C}\right)[10,14,36,37]$ have a positive effect on maternal temperature during cesarean delivery. While previous studies have recorded positive effects with these methods, those efforts have been insufficient in preventing inadvertent perioperative hypothermia $[5,10,11$, 13-16, 33-36].

In this retrospective observational cohort study, - in addition to standard intravenous/irrigation fluid warming - we evaluated preoperative and intraoperative active warming to prevent/limit thermal redistribution and heat loss. We used the Bair Paws ${ }^{\mathrm{TM}}$ warming gown for preoperative warming because it is a standard part of perioperative temperature regulation in our institution and allows mothers to choose their comfort level representing how patients use the device in real time. We used the Bair Hugger ${ }^{\text {TM }}$ full access underbody blanket during the procedure because (1) lower extremity active warming studies have not been effective, [5, 38] (2) upper body gowns billow significantly during use, encroaching on the mother's face and limiting access to the arms during the procedure, and (3) the underbody blanket provides for improved access for infant skin-toskin bonding immediately after delivery while continuing to deliver warmth to mother and child.

Our results are similar to other previous studies evaluated the efficacy of active warming before neuraxial block administration in conjunction with upper body active warming during the procedure $[9,18,28]$. de Bernardis studied 40 patients undergoing elective cesarean delivery and evaluated the Bair Paws ${ }^{\mathrm{TM}}$ gown in both the preoperative (total body) and intraoperative arena (upper body) [18]. The spinal anesthesia and the volume of warmed fluids $\left(37^{\circ} \mathrm{C}\right)$ was similar to our population but the duration of surgery was shorter at $60 \mathrm{~min}$ and BMI range smaller (29-30). Baseline temperatures (digital tympanic) were similar, and at the end of surgery temperatures were slightly higher than in our investigation $\left(36.2^{\circ} \mathrm{C}\right.$ vs. $\left.36.0^{\circ} \mathrm{C}\right)$ but the magnitude of changes between groups were similar. Horn found that $15 \mathrm{~min}$ of upper extremity active warming with fluid warming before an epidural anesthetic was effective in maintaining a normal temperature (tympanic thermocouple probe) in patients undergoing elective cesarean delivery [9]. The study, however, employed only epidural anesthesia and is limited by the practicality of performing preanesthetic active warming in the operative suite. Finally, in an evaluation of isolated preoperative active warming for 20 min using a full body system in addition to warmed intravenous fluids did not alter hypothermia or maternal comfort [28]. Based on the slight increase in temperature after use of the Bair Paws ${ }^{\mathrm{TM}}$ before surgery and no difference in the initial Foley temperatures that aspect of active warming may provide minimal if any benefit.

There were no differences in the secondary neonatal indicators of poor outcome (Apgar scores, placenta arterial $\mathrm{pH}$, base deficit) [30]. This finding is consistent with the work of Cobb [5] and Chung [14] who reported no differences in umbilical vein $\mathrm{pH}$ or Apgar scores and Grant [16] who also reported no difference in umbilical artery $\mathrm{pH}$ or Apgar scores in their trials despite improved thermal management. This is in slight contrast to the study of active warming by Horn [9]. While they observed differences in the core temperature between groups, the Apgar scores were similar despite significant aberrations in placental vein $\mathrm{pH}$ and base excess with passive warming.

As with any intervention or change in practice the benefits must be balanced with the time/effort to implement a change and costs. The time/effort of the logistics chain, using a preoperative warming gown and placing an underbody warming blanket on the operating room table are negligible. However, there are capital 
investment costs ( $\$ 1750.00$ each - $3 \mathrm{M}$ suggested list price) and the variable costs of the warming gown and underbody blanket for each procedure (\$14.00 and $\$ 16.00$ respectively - $3 \mathrm{M}$ suggested list price). However, actual costs are dependent on negotiated contracts which can reduce acquisition costs by as much a $50 \%$.

A criticism of this report is the lack of randomization and blinding. However, quasi-experimental designs are useful when internal validity threats (history, maturation, observation, and instrumentation) are addressed [20]. Though these challenges are more prominent in long term studies, they also need to be considered here. Historical and maturation challenges were minimal as this evaluation was conducted over a relatively short time frame ( 9 months) with a core faculty group providing both anesthetic and obstetrical services. This resulted in similar patient characteristics, anesthetic and surgical procedural times, equivalent environmental management, fluid administration and blood loss. In addition, there were no changes in measurement techniques over the time. Despite the interrupted time series design, it is unlikely that within the time frame of analysis there was a systematic variable or natural trend for patients to have decreased loss of temperature and in increased warming other than the associated addition of active warming to our passive warming methods.

Because this was a pragmatic application of change we did not control or systematically measure how patients used the Bair Paws ${ }^{\mathrm{ma}}$ warming gown before surgery. In daily practice patients regulate temperature delivery based on thermal comfort and not maximizing heat transfer which at times is intolerable [28].

Another criticism would be maintaining the intraoperative temperature at an average of $18.5^{\circ} \mathrm{C}$. While increased intraoperative temperature at $20-23^{\circ} \mathrm{C}$ may or may not further improve thermal management it is known to increase surgeon discomfort [17, 39]. When approaching this project we decided to evaluate the addition of active warming as the highest probability for a beneficial impact prior to systematically altering the operating room temperature.

\section{Conclusion}

In summary, we report a pragmatic initiative to reduce inadvertent perioperative hypothermia during cesarean delivery. As outlined, warmed intravenous and irrigation fluids, combined with pre and intraoperative active warming during elective repeat cesarean delivery maintained maternal temperature better with a decreased incidence of inadvertent perioperative hypothermia (< $36{ }^{\circ} \mathrm{C}$ ). The primary outcomes of temperature and inadvertent perioperative hypothermia at the end of surgery are driven by total body heat and the spinal anesthetic which causes vasodilation with redistribution and reduction in the core temperature. The longer surgical times in our population may have impacted the positive rewarming in the active warming group and may not be applicable in facilities with shorter surgical times. We did not observe benefits in the secondary neonatal and maternal outcomes. However, this evaluation is underpowered to detect differences in those outcomes.

\begin{abstract}
Abbreviations
C: Centigrade; SD: Standard deviation; FE: Fisher Exact; BMI: Body mass index; ASA: American Society of Anestheisologists; KS: Kolmogorov Smirnoff two sample test of non-parametric data.; CSE: Combined spinal epidural; BTL: Bilateral tubal ligation

Authors' contributions

Amie L Hoefnagel MD Conceptualization, Methodology, Writing - Original

Draft, Writing - Review \& Editing. Kristen L Vanderhoef MD Conceptualization, Methodology, Investigation, Writing - Review \& Editing. Anwar Anjum MD Investigation, Data Curation, Formal analysis, Writing - Original Draft, Writing - Review \& Editing. Venkata Damalanka MD Conceptualization, Methodology, Investigation, Data Curation, Saurin J Shah MD Supervision,

Conceptualization, Methodology, Writing - Review \& Editing, Carol A Diachun MD Conceptualization, Methodology, Investigation, Writing - Review \&

Editing. Paul D Mongan MD Supervision, Conceptualization, Methodology, Investigation, Data Curation, Formal analysis, Writing - Review \& Editing. The authors read and approved the final manuscript.
\end{abstract}

Funding

Department of Anesthesiology, University of Florida Jacksonville.

Availability of data and materials

The datasets used and/or analyzed during the current study are available from the corresponding author on reasonable request.

Ethics approval and consent to participate

see methods section.

Consent for publication

not applicable.

\section{Competing interests}

The authors declare that they have no monetary or non-financial conflict of interest with the any manufacturing entities listed in this manuscript.

\section{Author details}

'Department of Anesthesiology, University of Florida College of Medicine Jacksonville, 655 West 8th Street; Box C-72, Jacksonville, FL 32209, USA.

${ }^{2}$ Department of Anesthesiology \& Pain Medicine, University of Washington, Seattle, WA, USA.

Received: 8 February 2020 Accepted: 8 April 2020

Published online: 19 April 2020

\section{References}

1. Frank SM, Fleisher LA, Breslow MJ, Higgins MS, Olson KF, Kelly S, et al. Perioperative maintenance of normothermia reduces the incidence of morbid cardiac events. A randomized clinical trial. JAMA. 1997;277:1127-34.

2. Kurz A, Sessler DI, Lenhardt R. Perioperative normothermia to reduce the incidence of surgical-wound infection and shorten hospitalization. Study of wound infection and temperature group. N Engl J Med. 1996;334:1209-15.

3. Sessler DI. Complications and treatment of mild hypothermia. Anesthesiology. 2001;95:531-43.

4. Carpenter $\mathrm{L}$, Baysinger $\mathrm{CL}$. Maintaining perioperative normothermia in the patient undergoing cesarean delivery. Obstet Gynecol Surv. 2012;67:436-46.

5. Cobb B, Cho Y, Hilton G, Ting V, Carvalho B. Active warming utilizing combined IV fluid and forced-air warming decreases hypothermia and improves maternal comfort during cesarean delivery: a randomized control trial. Anesth Analg. 2016;122:1490-7. 
6. Caughey AB, Wood SL, Macones GA, Wrench IJ, Huang J, Norman M, et al. Guidelines for intraoperative care in cesarean delivery: enhanced recovery after surgery (ERAS(R)) society recommendations. Am J Obstet Gynecol. 2018.

7. Saito T, Sessler DI, Fujita K, Ooi Y, Jeffrey R. Thermoregulatory effects of spinal and epidural anesthesia during cesarean delivery. Reg Anesth Pain Med. 1998;23:418-23.

8. Sessler DI. Temperature monitoring and perioperative thermoregulation. Anesthesiology. 2008;109:318-38.

9. Horn EP, Schroeder F, Gottschalk A, Sessler DI, Hiltmeyer N, Standl T, et al.. Active warming during cesarean delivery. Anesth Analg. 2002;94:409-414, table of contents.

10. Yokoyama K, Suzuki M, Shimada Y, Matsushima T, Bito H, Sakamoto A. Effect of administration of pre-warmed intravenous fluids on the frequency of hypothermia following spinal anesthesia for cesarean delivery. J Clin Anesth. 2009;21:242-8.

11. Sultan P, Habib AS, Cho Y, Carvalho B. The effect of patient warming during caesarean delivery on maternal and neonatal outcomes: a meta-analysis. $\mathrm{Br}$ J Anaesth. 2015;115:500-10.

12. National Institute for Health and Clinical Excellence. Hypothermia: prevention and management in adults having surgery. Pathways Clinical Guideline 65. 2016.

13. Shaw CA, Steelman VM, DeBerg J, Schweizer ML. Effectiveness of active and passive warming for the prevention of inadvertent hypothermia in patients receiving neuraxial anesthesia: a systematic review and meta-analysis of randomized controlled trials. J Clin Anesth. 2017;38:93-104.

14. Chung SH, Lee BS, Yang HJ, Kweon KS, Kim HH, Song J, et al. Effect of preoperative warming during cesarean section under spinal anesthesia. Korean J Anesthesiol. 2012;62:454-60.

15. Chakladar A, Dixon MJ, Crook D, Harper CM. The effects of a resistive warming mattress during caesarean section: a randomised, controlled trial. Int J Obstet Anesth. 2014;23:309-16.

16. Grant EN, Craig MG, Tao W, McIntire DD, Leveno KJ. Active warming during cesarean delivery: should we SCIP it? Am J Perinatol. 2015:32:933-8.

17. Allen TK, Habib AS. Inadvertent perioperative hypothermia induced by spinal anesthesia for cesarean delivery might be more significant than we think: are we doing enough to warm our Parturients? Anesth Analg. 2018; 126:7-9.

18. de Bernardis RC, Siaulys MM, Vieira JE, Mathias LA. Perioperative warming with a thermal gown prevents maternal temperature loss during elective cesarean section. A randomized clinical trial. Braz J Anesthesiol (Elsevier). 2016;66:451-455.

19. Horn EP, Bein B, Bohm R, Steinfath M, Sahili N, Hocker J. The effect of short time periods of pre-operative warming in the prevention of peri-operative hypothermia. Anaesthesia. 2012;67:612-7.

20. Maciejewski ML, Curtis LH, Dowd B. Study design elements for rigorous quasi-experimental comparative effectiveness research. J Comp Eff Res. 2013;2:159-73.

21. Ogrinc G, Davies L, Goodman D, Batalden P, Davidoff F, Stevens D. SQUIRE 2.0-Standards for Quality Improvement Reporting Excellence-Revised Publication Guidelines from a Detailed Consensus Process. J Am Coll Surg. 2016;222:317-23.

22. Horn EP, Bein B, Steinfath M, Ramaker K, Buchloh B, Hocker J. The incidence and prevention of hypothermia in newborn bonding after cesarean delivery: a randomized controlled trial. Anesth Analg. 2014;118:997-1002.

23. Faul F, Erdfelder E, Lang AG, Buchner A. G*power 3: a flexible statistical power analysis program for the social, behavioral, and biomedical sciences. Behav Res Methods. 2007;39:175-91.

24. Cohen J. A power primer. Psychol Bull. 1992;112:155-9.

25. Allen TK, George RB, White WD, Muir HA, Habib AS. A double-blind, placebo-controlled trial of four fixed rate infusion regimens of phenylephrine for hemodynamic support during spinal anesthesia for cesarean delivery. Anesth Analg. 2010;111:1221-9.

26. Cork RC, Vaughan RW, Humphrey LS. Precision and accuracy of intraoperative temperature monitoring. Anesth Analg. 1983;62:211-4.

27. Kimberger $\mathrm{O}$, Cohen $\mathrm{D}$, Illievich $\mathrm{U}$, Lenhardt $\mathrm{R}$. Temporal artery versus bladder thermometry during perioperative and intensive care unit monitoring. Anesth Analg. 2007;105:1042-7. Table of contents.

28. Munday J, Osborne S, Yates P, Sturgess D, Jones L, Gosden E. Preoperative warming versus no preoperative warming for maintenance of Normothermia in women receiving Intrathecal morphine for cesarean delivery: a single-blinded, Randomized Controlled Trial. Anesth Analg. 2018; 126:183-9.

29. Faraone SV. Interpreting estimates of treatment effects: implications for managed care. P T. 2008;33:700-11.

30. Armstrong L, Stenson BJ. Use of umbilical cord blood gas analysis in the assessment of the newborn. Arch Dis Child Fetal Neonatal Ed. 2007;92: F430-4.

31. Hui CK, Huang CH, Lin CJ, Lau HP, Chan WH, Yeh HM. A randomised double-blind controlled study evaluating the hypothermic effect of 150 microg morphine during spinal anaesthesia for caesarean section. Anaesthesia. 2006:61:29-31.

32. Chan WW, Morley-Forster PK, Vosu HA. Temperature changes and shivering after epidural anesthesia for cesarean section. Reg Anesth. 1989;14:48-52.

33. Goyal P, Kundra S, Sharma S, Grewal A, Kaul T, Singh M. Efficacy of intravenous fluid warming for maintenance of core temperature during lower segment cesarean section under spinal anesthesia. J Obstet Anaesth Critical Care. 2011;1:73-7.

34. Paris $L G$, Seitz M, McElroy KG, Regan M. A randomized controlled trial to improve outcomes utilizing various warming techniques during cesarean birth. J Obstet Gynecol Neonatal Nurs. 2014;43:719-28.

35. Woolnough M, Allam J, Hemingway C, Cox M, Yentis SM. Intra-operative fluid warming in elective caesarean section: a blinded randomised controlled trial. Int J Obstet Anesth. 2009;18:346-51.

36. Jorgensen HS, Bach LF, Helbo-Hansen HS, Nielsen PA. Warm or cold saline for volume preload before spinal anaesthesia for caesarean section? Int J Obstet Anesth. 2000;9:20-5.

37. Workhoven MN. Intravenous fluid temperature, shivering, and the parturient. Anesth Analg. 1986;65:496-8.

38. Butwick AJ, Lipman SS, Carvalho B. Intraoperative forced air-warming during cesarean delivery under spinal anesthesia does not prevent maternal hypothermia. Anesth Analg. 2007;105:1413-9. Table of contents.

39. Frank SM, El-Rahmany HK, Cattaneo CG, Barnes RA. Predictors of hypothermia during spinal anesthesia. Anesthesiology. 2000;92:1330-4.

\section{Publisher's Note}

Springer Nature remains neutral with regard to jurisdictional claims in published maps and institutional affiliations.
Ready to submit your research? Choose BMC and benefit from:
- fast, convenient online submission
- thorough peer review by experienced researchers in your field
- rapid publication on acceptance
- support for research data, including large and complex data types
- gold Open Access which fosters wider collaboration and increased citations
- maximum visibility for your research: over $100 \mathrm{M}$ website views per year
At BMC, research is always in progress.
Learn more biomedcentral.com/submissions 